Est Ag 47 (2012) 57-71

\title{
¿Progreso o estancamiento en el diálogo entre teología y ciencia?
}

\author{
LLUÍs OVIEDO \\ Profesor del Antonianum de Roma
}

ABSTRACT: Several qualified voices have complained in recent years about the impasse perceived in the development of science-and-theology, since no progress is any longer registered, and the same arguments are repeated. Against this opinion, manifold reasons emerge calling for greater engagement from both sides of this interdisciplinary endeavor: the broadening of horizons; the persistence of unresolved issues claiming for greater effort; the rise of new challenges after recent scientific discoveries; the development of philosophical consequences and theological applications; the incorporation of new methods, like the empirical ones in theology; and the pending apologetic questions, calling for better answers.

KEY WORDS: science, theology, interdisciplinary endeavor, broad horizons, scientific discovery.

RESUMEN: Varias voces cualificadas se han quejado en los últimos años acerca de la percepción de estancamiento en el desarrollo de la ciencia y la teología, ya que no se ha registrado ningún progreso, y los mismos argumentos se repiten. En contra de esta opinión, surgen múltiples razones, reclamando un mayor compromiso por parte de ambos lados en este esfuerzo interdisciplinario: la ampliación de horizontes, la persistencia de problemas no resueltos reclamando un mayor esfuerzo, el surgimiento de nuevos retos después de los descubrimientos científicos recientes, el desarrollo de las consecuencias filosóficas y las aplicaciones teológicas, la incorporación de nuevos métodos empíricos, en la teología, y las cuestiones apologéticas pendientes que piden mejor respuesta.

PALABRAS CLAVE: ciencia, teología, interdesciplinar, horizontes abiertos, descubrimientos científicos. 
Desde hace algunos años diversos autores que estudian la interacción entre ciencia y teología se preguntan si se ha alcanzado una cierta 'saturación' en ese campo, y si tal situación cuestiona el desarrollo de esta 'sub-disciplina'. Es opinión común que un área científica sin posibilidad de progreso limita su alcance y reduce drásticamente su nivel de investigación.

Las voces a las que me refiero son cualificadas. Michel Ruse, uno de los protagonistas de dicho diálogo, se quejaba hace algunos años del bajo nivel académico de una buena parte de la producción en ese campo, lo que sugeriría un cierto agotamiento de la materia y una repetición de los argumentos ${ }^{1}$. Willem Drees, actual director de la revista Zygon, ha expresado similares motivos de insatisfacción o de duda en un libro reciente. En su opinión se percibe una "falta de progreso" en ese campo a causa de la dificultad para considerar de forma más rigurosa los presupuestos asumidos y la finalidad de dicho estudio interdisciplinar ${ }^{2}$. Aparte, otra queja se refiere a la falta de interés que el trabajo en ese ámbito despierta en amplios sectores, tanto de la teología como de la ciencia. Además, se ha abusado excesivamente de desarrollos de tono retórico e 'inspiracional' en la llamada 'teología de la ciencia', que parecían esquivar un mayor compromiso con la investigación científica y sus resultados ${ }^{3}$.

Siguiendo esta pista, podría ocurrir, cambiando los términos, lo que ha pasado con la llamada 'teología de las religiones': que tras muchos debates ha llegado a un punto en que se han fijado las distintas posiciones, se hen debatido todos los argumentos en uno u otro sentido, y se ha llegado a una especie de estancamiento en el que difícilmente se podía concebir algo nuevo o enfoques que pudieran desbloquear la situación. También en ese caso se acaba en discursos de tipo retórico y declaraciones conciliadoras y de buena voluntad.

Por otro lado el análisis estadístico de la frecuencia en que aparecen términos como 'ciencia y religión' o 'ciencia y teología' confirmaría dicha percepción de cierta caída a partir del 2005. Otro dato empírico a tener en cuenta es el carácter más bien limitado de las asociaciones, congresos y publicaciones que se dedican a estos aspectos. Mi experiencia personal en la Sociedad Europea para el Estudio de la Ciencia y la Teología (ESSSAT) confirma dicha impresión de escaso crecimiento.

\footnotetext{
${ }^{1}$ Michael Ruse, "My Journey in the World of Religion-and-Science”, Zygon, 42-3, 2007, pp. $577-582$.

${ }^{2}$ Willem B. Drees, Religion and Science in Context: A Guide to the Debates, Abingdon: Routledge, 2010.

${ }^{3}$ Barbara Herrnstein Smith, Natural Reflections: Human Cognition at the Nexus of Science and Religion, Yale University Press, New Haven, CT, London, UK, 2009, pp. 97 ss.
} 
En el campo de la teología de las religiones se establecieron tres posiciones fundamentales: exclusivismo, inclusivismo y pluralismo. En el diálogo con la ciencia, ya Barbour fijó las cuatro posiciones conocidas y que repiten todos los manuales. Se podría decir que las cosas siguen estando en cierto modo igual que a mitad de los años ochenta, y que las opciones no se han movido demasiado.

Es cierto que si se trata de las dos primeras posiciones, el conflicto o la inconmesurabilidad, no hay progreso que valga. Tampoco cabe esperar mucho de la tercera posición, que aboga por una síntesis en la que la teología acaba asimilándose a los avances de la ciencia. La cosa seguramente cambia si se asume un modelo de diálogo que respeta la identidad de las partes y busca un mutuo enriquecimiento. Hay motivos para pensar que, en algunos campos, las orientaciones se han fijado, o se ha alcanzado una cierta estabilidad que se refleja en los manuales, y se han estandarizado las diversas vías de recepción de las visiones más sedimentadas en cosmología y biología. De todos modos me resisto a pensar que buena parte del trabajo ya se ha realizado, que queda más bien poco que estudiar, o que sería una pérdida de tiempo dedicar la investigación teológica a ese sector, en donde ya casi todo ha sido dicho o no quedan zonas por explorar. Dicha percepción parece justificar más bien actitudes descomprometidas y una cierta 'pereza intelectual' a la hora de afrontar desafíos que distan mucho de encontrar una buena respuesta teológica. Por otro lado, si aplicáramos ese mismo criterio al desarrollo reciente de la teología fundamental, la situación podría revelarse todavía peor, en el sentido de carencia de innovación, o repetición de los mismos temas que hace veinte años.

En lo que sigue, intentaré justificar en qué medida esta llamada 'subdisciplina' sigue presentando ingentes retos, requiere un mayor compromiso por parte de la teología, y dista mucho de haber alcanzado un punto de saturación. Otra cosa es que los resultados de esta interacción o el esfuerzo que despliegan quienes siguen consagrados a ella, sean tomados en serio por la comunidad académica establecida en las dos áreas afectadas.

Básicamente, me referiré a varios escenarios de renovación: la ampliación de los horizontes disciplinares; la existencia de cuestiones irresueltas y que siguen reclamando mayor esfuerzo; la emergencia de nuevos retos en la investigación más reciente; el desarrollo de las consecuencias filosóficas y de las aplicaciones teológicas; la incorporación de nuevas metodologías, incluyendo las empíricas en teología; y las cuestiones apologéticas pendientes. Mi objetivo es informar a los colegas sobre qué es lo que se está moviendo en este campo y dónde habría que fijar más la atención. 


\section{Ampliación de los horizontes disciplinares}

La impresión que podía desprenderse de una revisión de la bibliografía disponible hasta hace algunos años era que el diálogo entre ciencia y teología se ocupaba fundamentalmente de cuestiones cosmológicas y del gran tema en torno al evolucionismo y sus consecuencias para la fe cristiana. Un repaso al índice de una obra de síntesis publicada por Ian Barbour en 20024, nos da una idea de los temas centrales: Dios y la evolución; Evolución, genética y la naturaleza humana; Neurociencia, inteligencia artificial y la naturaleza humana; Dios y la naturaleza: una visión en clave de proceso; Teología, ética y el ambiente. En general parece que estos han sido los 'temas estrella', o que han captado más la atención.

No obstante, un meta-análisis de los libros y artículos publicados más recientemente y que pueden tener una cierta relevancia para la interacción entre ciencia y teología, depara algunas sorpresas, en el sentido de que han entrado en escena nuevos temas, que han supuesto una ampliación del panorama. Esta ampliación afecta sobre todo al ámbito antropológico y al llamado 'estudio científico de la religión'. Trataré de exponer brevemente en qué consiste el nuevo escenario que configuran estas recientes entradas.

En primer lugar, las cuestiones antropológicas no estaban ausentes del tratamiento anterior, pero no habían incorporado una buena parte de las aportaciones o desarrollos científicos que se han promovido en la última década. De hecho, los estudios genéticos, la aplicación más amplia del enfoque biológico evolucionista, o los análisis neurológicos plantean nuevos retos y oportunidades que no deberían ser ignorados. Cabe afrmar que se registra un claro fermento en ese campo, aunque buena parte del progreso en curso pueda ser entendido de forma peyorativa, en el sentido de afectar negativamente a la antropología teológica, pero claro, eso es otro tema.

La cuestión que se plantea es si se puede hablar de 'progreso en el estudio de ciencia y teología' cuando la mayor parte de las aportaciones más recientes en el área antropológica se sitúan en las antípodas de la visión cristiana, lo que puede ciertamente causar perplejidad y alejar -más que acercar- a los teólogos que pudieran sentirse interesados en ese diálogo. En primer lugar, conviene advertir desde el principio que dicha interacción no es nada fácil, y que nadie debería hacerse ilusiones, esperando que la ciencia provea argumentos en favor de cierto 'concordismo' o al menos res-

\footnotetext{
${ }^{4}$ Ian Barbour, Nature, Human Nature, and God, Minneapolis, Fortress Press 2002; también resulta muy útil la obra más reciente de Keith Ward, The Big Questions in Science and Religion, West Conshohocken, PA: Templeton, 2008.
} 
pete la visión tradicional cristiana. Mi experiencia en los años de dedicación a este campo es que a menudo el impacto de las ciencias es negativo para la teología y la fe, y que sólo tras una cierta maduración se logra acceder a visiones capaces de fecundar y renovar el discurso cristiano, para actualizarlo y volverlo significativo.

Por otro lado sería reductivo afirmar que el desarrollo científico sólo depara sorpresas desagradables para los creyentes. En contadas ocasiones el debate en curso pone en evidencia la debilidad de las posiciones que se consideraban más firmes y que podían plantear una reducción antropológica. Un caso reciente es la profunda revisión que sufre el modelo más reductivo de la 'auto-conciencia', que había perdido su perfil en la consideración antropológica más estándar, con lo que se veían en entredicho la libertad y la especificidad humanas. Ahora dicha dimensión es reivindicada en base a la evidencia que provee la psicología experimental y la neurología.

El conocimiento del ser humano inspirado en modelos biológicos debe ser asumido en aras a un sano realismo, y a la superación de idealizaciones antropológicas que han sido una fuente de problemas en la vida cristiana, eclesial y en la teología espiritual. Quizás esas aportaciones no hagan más que recordarnos temas y enfoques que ya había desarrollado San Agustín, pero que es muy bueno que sean confirmados desde una visión más científica y empírica. Además, no todo es pesimista en este campo; los estudios sobre el altruismo prosperan de forma intensa y proveen nuevos escenarios. De hecho este ha sido uno de los temas más debatidos en los últimos meses, tras una provocativa publicación de Edward Wilson en la revista Nature ${ }^{5}$.

$\mathrm{El}$ otro frente recientemente abierto y de gran relevancia para el diálogo entre ciencia y teología corresponde al gran desarrollo que conoce el llamado "estudio científico de la religión". En general se refiere a tres programas relativamente distintos: el neurológico, el cognitivo, y el biológico, aunque a menudo se registran interferencias entre ellos. En breve, dichos programas intentan ofrecer explicaciones más plausibles, es decir, de mayor capacidad heurística, del fenómeno religioso. Sus autores están convencidos de contar actualmente con instrumentos de análisis que no estaban a disposición en décadas anteriores, por lo que ni la antropología clásica ni las explicaciones en clave sociológica, psicológica o fenomenólogica convencionales podían aportar los resultados que ahora se descubren.

Es evidente que este nuevo desarrollo afecta - a menudo negativamente- a la reflexión teológica y presenta serios desafíos desde un punto

\footnotetext{
${ }^{5}$ Martin A. Nowak, Corina E. Tarnita, and Edward O. Wilson, "The evolution of Eusociality", Nature, Vol. 466/26 August 2010, doi:10.1038/nature09205.
} 
de vista apologético. A grandes rasgos ese programa resulta claramente reductivo y obedece a un intento de 'naturalizar' la fe religiosa. Si nuestros colegas logran llevar a término su objetivo de proveer una teoría de gran poder explicativo que reduzca la experiencia religiosa a factores puramente naturales, entonces la causa de la teología quedaría ampliamente en entredicho. De ahí que, a pesar de las muchas debilidades y decepciones de esta línea de investigación, sea necesario tomarla en serio si queremos evitar las desastrosas consecuencias que reportaría una divulgación poco crítica. De hecho algunos de los exponentes más duros del 'nuevo ateísmo', como Dawkins y Dennett, se han servido de argumentos que proveían estas teorías.

De todos modos conviene recordar que, una vez más, dicha investigación aporta en ocasiones inspiraciones útiles para la teología, en concreto a la teología de la fe o del actus credendi, que puede verse iluminada a partir de estas propuestas. Trataré de este punto más ampliamente en otro apartado.

La amplicación de horizontes se produce, por último, como consecuencia de una inclusión de disciplinas más allá de las llamadas 'ciencias naturales', que parecían acaparar un excesivo protagonismo en el diálogo en curso. Una visión más amplia considera injusto dejar fuera de este diálogo otros campos que pretenden un nivel de rigor equiparable a cualquier otra ciencia, como las ciencias terapéuticas y las ciencias sociales, en especial la economía y la sociología. También los desarrollos más experimentales de la psicología deberían ser incluídos en la lista de candidatos a una interacción más madura. Seguramente el tratamiento clásico de la subdisciplina partía de la prioridad de las ciencias naturales sobre las demás, que ocuparían un papel más derivado y no gozarían del rigor y controles que elevan la fiabilidad de la física o la biología. Sin embargo, sería un error seguir ese criterio -que distingue entre 'ciencias de primera clase' y 'de segunda'- e ignorar la riqueza de aportaciones, así como de retos que derivan de dichos estudios para la fe.

\section{Cuestiones pendientes}

Cualquiera que sea consultado sobre la situación actual en el campo del diálogo entre ciencia y teología confirmará que quedan bastantes cuestiones por resolver. No obstante, el pesimismo deriva más bien del hecho de que se repiten las respuestas o las orientaciones que ya dieron algunos autores desde los años ochenta. Un típico ejemplo se refiere al problema de cómo concebir la acción de Dios en un mundo dominado por la causalidad física, y que no parece dejar espacio para intervenciones de orden sobrenatural. Ya se han 
establecido las soluciones 'estándar': el recurso a la mecánica cuántica, el papel que juega la información, la física del caos, y poco más ${ }^{6}$. Llegados a ese punto da la impresión de que el problema no está del todo resuelto, y que de todos modos no queden muchas más cartas que jugar.

Algo parecido podría afirmarse respecto de las cuestiones que sigue planteando el evolucionismo y sus distintas aplicaciones. Se han escrito muchos libros, pero la sensación es que los argumentos empleados siguen siendo similares, es decir, no se registra demasiado progreso. No obstante quedan varios cabos sueltos, es decir, no podemos pretender que la cuestión está 'cerrada' y que el tema no da más de sí.

Todas las ciencias conocen 'cuestiones pendientes' y a ellas se dedican una buena parte del esfuerzo y los recursos disponibles. En la física de partículas, se siguen buscado, con ingentes inversiones, los componentes más elementales de la materia. No parece que se registre tampoco un gran progreso en un campo que desde hace décadas cautiva a los mejores físicos: encontrar una teoría unificada en grado de coordinar la teoría de la relatividad y la cuántica. En biología todavía no se ha encontrado, a pesar de los muchos esfuerzos, el proceso químico que está en la base de las dinámicas vivas de auto-organización y auto-reproducción. Tampoco se ha logrado dar con una remota solución al problema de las bases neurológicas que explican el fenómeno de la auto-conciencia. Todos estos enigmas irresueltos no suelen ser interpretados, a pesar de todo, como síntomas de agotamiento de las respectivas disciplinas, a pesar de que parecen estancados desde hace veinte años, sino que son vistos como retos que continúan animando la investigación y justifican amplias inversiones de capital material y humano. La 'inversión teológica' dedicada a afrontar los retos pendientes en el diálogo con la ciencia, en comparación con lo que se invierte -por ejemplo-en el intento de identificar el 'Boson de Higgs', es francamente ridícula.

Por otro lado, el repaso a la bibliografía reciente sí muestra signos de progreso, o al menos de no-agotamiento, en lo que se refiere a esas grandes cuestiones, en especial por que, como se verá a continuación, se registran desarrollos en el interior de las ciencias y debates de gran vivacidad que abren algunas nuevas puertas al desarrollo teológico. Por consiguiente, no

${ }^{6}$ Nicholas Saunders, Divine Action and Modern Science, Cambridge and New York: Cambridge University Press, 2002; por otro lado un título más reciente sugiere que sí ha habido progreso: Robert John Russell, Nancey Murphy, William R. Stoeger S.J. (Eds.), Scientific Perspectives on Divine Action: Twenty Years of Challenge and Progress, Vatican Observatory FND NDUP. 
habría que asumir como un hecho negativo el que la teología siga encontrando en su camino cuestiones de difícil solución, o que no encuentre una respuesta definitiva y claramente satisfactoria. Siendo esta una situación común, debería más bien incentivar un nivel más comprometido de investigación, en búsqueda de soluciones mejores, como ocurre en todas las ciencias. Otra cosa es que se prefiera aceptar de forma poco crítica las conclusiones alcanzadas y que se abandone una investigación que exige mayor esfuerzo. En ese caso el problema no es tanto la sub-disciplina, sino la falta de empeño teológico ante los nuevos retos que se plantean desde la parte más dinámica del conocimiento humano.

\section{Nuevos retos en la investigación reciente}

Desde mi punto de vista el dato que más cuestiona la opinión del estancamiento de la ciencia-y-teología es el hecho de que se producen constantemente progresos y se difunden noticias que obligan a replantear -a veces en profundidad- las visiones ya adquiridas. En los dos párrafos anteriores ya se ha hecho alusión a estos desarrollos, pero ahora toca profundizar en su alcance y significado para la interacción propuesta.

Una primera 'sacudida' ha sido provocada por el impacto del llamado 'Nuevo ateísmo'. Quizás la carta de nacimiento de ese movimiento fue la publicación en 2006 del conocido libro de Richard Dawkins, La desilusión de Dios. Se trataba de una crítica feroz a la religión por parte de un científico, que recurre a menudo a argumentos científicos. Hasta entonces algunos habían pretendido que el desarrollo científico era o debía ser indiferente a las cuestiones religiosas[me permito recordar que en nuestras Jornadas del 2005, celebradas en Burgos, nuestro colega Sequeri consideraba que la ciencia no afectaba a la cuestión de la creencia y el ateísmo]. El hecho es que dicha obra dio lugar a una especie de 'género literario' de tono divulgativo que ha producido decenas de títulos en los que se extraen las consecuencias más negativas para la fe religiosa a partir de la ciencia. Pero además, dicho desarrollo ha provocada una oleada de obras de tono decididamente apologético, que cuenta con muchos más títulos en respuesta y que aportan una profunda crítica a las tesis de Dawkins, Dennett y otros. Lo que interesa de este fenómeno cultural y editorial es que la provocación por parte de los nuevos ateos científicos ha motivado la reacción de muchos teólogos y autores cristianos que han encontrado una ocasión para desplegar argumentos a favor de la plausibilidad y la relevancia de la fe en una cultura marcada profundamente por la mentalidad

científica. Otra cosa es la menor atención que quizás se ha prestado dentro de 
la sub-disciplina a esos desarrollos, que eran considerados menos relevantes. Probablemente se trata de un síntoma de algunos de los problemas que han afectado a la orientación dominante en ese campo, y que hay que revisar. De todos modos, la crítica atea ha vuelto a poner de moda la 'cuestión de Dios' lo que no es poco en un ambiente tan secularizado.

Quien esté atento a los desarrollos en los campos científicos más sensibles a la teología se dará cuenta de que no se puede nunca bajar la guardia, y ni mucho menos pensar que las cosas ya están bastante claras, por lo que sólo nos queda rumiar los resultados adquiridos y darles un formato digerible para los creyentes. Creo que hay varios ejemplos que nos animan a seguir trabajando y a buscar nuevas formas de interacción.

En primer lugar, el campo cosmológico. Están pasando muchas cosas y se han publicado en los últimos meses varios libros que seguramente obligan a replantear las estrategias tradicionales en torno a cómo recuperar la doctrina de la creación en el contexto que configura la cosmología física. Las obras de Hawking y Mlodinow, o la más reciente de Penrose, entre otras, invitan -desde sus hipótesis de trabajo o sus propuestas sobre el origen del cosmos- a ensayar respuestas teológicas que sigan validando la doctrina cristiana que sostiene la fe en Dios como creador del universo.

¿Qué decir de los interminables debates en torno a la evolución como desarrollo auto-suficiente de la naturaleza viva? No pasan los meses sin que nos sintamos sorprendidos por tomas de posición vehementes en torno a la cuestión del diseño, de la teleología, o de la 'sintonía fina'. En definitiva, el problema de si es más plausible la explicación exclusivamente evolucionista o bien una alternativa que añade un elemento externo o trascendente, dista mucho de estar resuelta, o de satisfacer a la mayoría.

El campo antropológico no deja de deparar sorpresas. Hace algunos años se decidió -por fin- la cuestión del monogenismo en los orígenes de nuestra especie, tras extenuantes discusiones y el espaldarazo que supusieron los análisis del DNA mitocondrial. Ahora se añaden año tras año descubrimientos que plantean serias cuestiones a la antropología teológica. Hace algunos meses un instituto de investigación alemán encontró evidencia sobre la presencia de partes del genoma de los Neandertalenses en el genoma humano, lo que implicaría una relación entre ambas especies y, por consiguiente, abre un interrogante sobre la pretendida exclusividad de la especie humana. Los recientes debates en torno al altruismo, protagonizados por Edward Wilson y su equipo ${ }^{7}$, ponen de nuevo sobre la mesa cuestiones

${ }^{7}$ Martin A. Nowak, Corina E. Tarnita \& Edward O. Wilson, The Evolution of Eusociality, Nature, 466, (26 August 2010), 1057-1062. 
de gran calado sobre la capacidad humana para hacer el bien y sus orígenes biológicos. Es de gran interés que dichas investigaciones estén dando al traste con el dogma del 'individualismo metodológico' en las ciencias biológicas, y abran las puertas a modelos más colectivos de selección natural.

Las novedades se producen también en los estudios neurológicos y cognitivos, con consecuencias de largo alcance para todos. Basta asomarse a los congresos en torno a estos temas para advertir lo animado de los debates y las aportaciones más recientes que cuestionan posiciones ya asentadas. El tema de la 'auto-conciencia' es uno de los que conocen desarrollos más interesantes, en el sentido de superar las visiones más fisicalistas y reductivas. Pero también los abundantes estudios sobre biología y cognición de lo religioso ofrecen materiales para la reflexión teológica, e invitan claramente a entrar en la discusión; de hecho resulta grave la ausencia de los teólogos en los ambientes y publicaciones en los que se debaten los avances en esos campos. De nuevo no parece que el problema sea la extenuación de la materia o el agotamiento de los campos de interacción, sino la falta de voluntad o interés para entrar en dichos ambientes y dejarse interpelar por los avances más o menos reales- que se registran en un campo tan sensible para la fe y su reflexión. Si el sentido religioso puede reducirse a mecanismos cognitivos o a un cierto 'interés biológico', entonces 'tenemos un problema'.

\section{El desarrollo de las consecuencias filosóficas y de las aplicaciones teoló- gicas}

Confío en que no sorprenda a nadie afirmar que uno de los campos más prometedores del desarrollo de la teología fundamental, en continuidad con el programa apologético que una vez constituía su núcleo, es el de la filosofía de la religión. Al menos así lo entienden un grupo de filósofos cristianos y de jóvenes teólogos que desarrollan argumentos, sobre todo en el ámbito de la tradición analítica, sobre la realidad de Dios, sus atributos y actuación, sin ningún rubor y con la convicción de que se trata de temas que dignifican a la reflexión teológica. Este programa puede leerse como un intento de asumir el motivo anselmiano del maius quod cogitare potest. Pero además, buena parte del desarrollo filosófico en el ambiente anglo-americano se concentra hoy en cuestiones que derivan de la recepción del método y de las hipótesis de trabajo científicas, con clarísimas repercusiones teológicas.

En primer lugar, la cuestión más grave se plantea en torno al llamado 'naturalismo', a su alcance y consecuencias. El debate se centra en verificar si un conocimiento de la realidad en clave exclusivamente natural, es decir 
física, basta para hacer las cuentas con la misma, o si hay espacio para comprender otras dimensiones de lo real, sobre todo en lo que se refiere a las dimensiones de conciencia. El reduccionismo es una pieza clave en el método científico, pero la cuestión estriba en comprender sus límites y ámbitos de aplicación. En la discusión corriente se pone en evidencia que el exceso de reduccionismo impide una comprensión más científica de algunos aspectos de la realidad, que implican un cierto grado de 'emergencia' respecto del nivel puramente físico ${ }^{8}$. De nuevo, si esas cuestiones no se resuelven desde una reflexión filosófica más comprometida, la teología se verá en serios apuros.

Conviene recordar que una buena parte de los debates señalados son muy recientes, y que en este caso se asiste a un claro progreso. Eso mismo ocurre en relación con los intentos de comprender la libertad de actuación, o la capacidad de decisión voluntaria que había sido puesta en entredicho por algunas interpretaciones precipitadas de la investigación neurológica. Las valoraciones más recientes desde una recepción filosófica de los avances registrados indican que hay un amplio espacio para concebir la decisión racional y consciente, que es la base de cualquier antropología de la libertad, y por ende, de cualquier antropología teológica. Ya se ha aludido además a los debates sobre la forma de concebir a la divinidad y su acción en el mundo cuando se tienen en cuenta los datos de la ciencia.

No obstante, desde mi punto de vista, lo que queda más por desarrollar es la aplicación teológica de motivos e inspiraciones que proceden de las ciencias, y que en ocasiones plantean retos, y en otras facilitan oportunidades. De hecho la ciencia a menudo cierra algunas puertas a la teología, pero abre al mismo tiempo otras e incluso algunas ventanas que ofrecen nuevas vistas hasta ese momento desconocidas.

Dejo para el siguiente párrafo las cuestiones metodológicas, que merecen una mención aparte. Interesa de momento centrarse en los campos que requieren un mayor esfuerzo de asimilación por parte de los teólogos, sobre todo los fundamentales. Conviene primero aclarar una premisa importante. Cuando se trata de la relación entre ciencia y teología, no se habla de un impacto mutuo o de un situación que afecta por igual a cada una de

${ }^{8}$ Steven Horst, Beyond Reduction: Philosophy of Mind and Post-Reductionist Philosophy of Science, Oxford University Press, Oxford - New York 2007; Philip Clayton and Paul Davies (Eds.), The Re-Emergence of Emergence: The Emergentist Hypothesis from Science to Religion, Oxford University Press, Oxford - New York 2006; Georg Gasser (Ed.), How Successful is Naturalism? Ontos Verlag, Frankfurt -Paris 2007. 
las partes. Sería una pía ilusión. En realidad a la inmensa mayoría de los científicos les trae sin cuidado cómo reaccione la teología o el significado de los avances de la ciencia para la fe. No hay simetría en absoluto: a la teología sin embargo sí le afectan ciertos desarrollos científicos y sus consecuencias, y sería demasiado arriesgado pretender ignorarlo. Aunque a priori pueda concebirse una experiencia de fe a salvo de dicho impacto, y en la práctica se cuenten muchos creyentes que viven su fe 'inmunizados' de los asaltos de la razón científica, a la larga, de forma empírica, cada vez son más las personas a las que afecta la representación científica de la realidad, que va volviendo superfluo el recurso a la fe y a la esperanza religiosa ${ }^{9}$. Por consiguiente la tarea principal en la que nos sentimos implicados no es tanto convencer a los científicos del valor de nuestras creencias y doctrinas para su propia actividad de investigación -lo que también hay que hacer- sino convencer a los creyentes de que la fe cristiana es compatible con la mentalidad científica, y que incluso puede crecer en ese específico campo del diálogo entre fe y razón, que tanto preocupa al Papa Benedicto XVI.

Lo repito, creo que se da un considerable retraso en la recepción y asimilación de las consecuencias teológicas de los avances científicos, sobre todo en los campos más sensibles, como el tratado de creación, la antropología teológica (el tema del pecado original, por ejemplo) y el tratado de fe como parte de la teología fundamental. Por supuesto el arco puede ampliarse si se asume la influencia de las ciencias sociales -como las teorías de la organización- en la eclesiología; los estudios rituales en la sacramentaria; y todo el impacto que los anteriores desarrollos tienen en la moral y la espiritualidad. Quien pretenda que ya no queda trabajo, o que todo lo que había que decir ya ha sido dicho, comete una temeridad o justifica su inacción.

Varios de los ejemplos indicados a lo largo de esta exposición pueden ser aducidos de nuevo con el fin de tomar conciencia de lo que aún queda por hacer. Sorprende la lentitud en la recepción de los estudios cognitivos de la religión, incluso en uno de los campos más sensibles a las novedades metodológicas, como son los estudios bíblicos, en los que todavía son escasos los intentos de aprovechar el potencial hermenéutico de las propuestas sobre los 'sesgos cognitivos', uno de los puntos de mayor interés. Considero

\footnotetext{
${ }^{9}$ Este es el argumento principal de muchos pensadores enraízados en la concepción científica: no pretenden -ni pueden- demostrar que Dios no existe, sino sólo que dicha hipótesis deja de ser necasaria ante el avance de la ciencia; un ejemplo reciente es: Peter Atkins, On Being: A Scientist's Exploration of the Great Questions of Existence, Oxford, New York: Oxford University Press, 2011.
} 
que, en general la teología puede ganar mucho si se atreve a entrar en el campo de los estudios cognitivos, del mismo modo que han ganado otras disciplinas humanísticas asuminendo inspiraciones y métodos de ese signo: la historia, los estudios literarios, la filosofía, la sociología o la antropología.

¿En qué podría consistir un 'giro cognitivista' en teología? Básicamente en la asunción de una clave de lectura que enfatiza el papel jugado por los procedimientos mentales, sus posibilidades, límites y sesgos, a la hora de concebir la divinidad, su actuación en el mundo, su interacción con los humanos en la historia, la idea de 'gracia', la cuestión del lenguaje y del comportamiento religioso, e incluso a la hora de organizar mejor los modelos o estilos teológicos, que seguramente siguen pautas cognitivas bastante identificables. Esta también es una misión de la teología fundamental: organizar el propio campo, en ocasiones un tanto confuso.

\section{La incorporación de nuevas metodologías}

Probablemente uno de los campos más prometedores y todavía por explorar en la interacción con la ciencia consiste en la asimilación de orientaciones metodológicas en grado de reforzar la validez del discurso teológico y de conferir mayor rigor a sus resultados.

En general la teología puede aprender mucho del método científico, y puede sacar gran partido de esas lecciones. En primer lugar está la asunción de una actitud más falibilista, es decir, que acepta la posibilidad del error en las interpretaciones que propone, que son siempre coyunturales o sometidas a contingencias fuera de nuestra gestión. En segundo lugar, la necesidad de asumir mayores controles sobre la calidad de los propios argumentos, lo que implica someter la producción teológica al examen de colegas bien informados y que puedan rastrear a tiempo posibles fallos o carencias. Tercero, la necesidad de verificar con el tiempo los resultados de las propias propuestas y su impacto efectivo para la fe y la Iglesia. Y cuarto, la necesidad de tomar muy en serio los datos que proceden de la investigación científica y que tienen especial relevancia para las cuestiones teológicas. No toda la teología debe incorporar un formato 'más científico', se trata sólo de hacer que una parte de la misma asuma esa responsabilidad, la parte que debe comprometerse más en el diálogo con la ciencia, y que debe reflejar ciertos requisitos de rigor.

Otra sugerencia se refiere a la asunción de métodos más empíricos y experimentales en la investigación teológica. Por un lado, se trata de un requisito si los teólogos quieren ser admitidos en los foros en los que se discuten las aproximaciones experimentales a la religión, así como sus 
consecuencias. Pero además, parece que dichos métodos son cada vez más necesarios a la hora de 'leer los signos de los tiempos', que por su propia naturaleza tienen un carácter empírico y requieren el recurso a métodos adecuados. Por otro lado, la necesidad antes señalada de verificar los resultados de las propuestas teológicas exige la aplicación de métodos empíricos para constatar el alcance de dichos efectos, sobre todo cuando no se puede decidir 'a primera vista' o dichos resultados son disputados o sistemáticamente ignorados.

Las cuestiones eclesiológicas cobran dimensiones nuevas cuando se asume una perspectiva más empírica, lo que implica una decidida superación del idealismo que ha evitado una percepción más realista de la organización eclesial, y capaz de afrontar mejor su difícil situación y las tribulaciones que atraviesa.

Se abre ante los teólogos un campo inmenso de posibilidades metodológicas todavía por explorar y que en su aplicación haría de la teología una disciplina más creíble y sobre todo más apta para un diálogo efectivo con las ciencias. A veces da la impresión de que lo que falla o se echa de menos en esa interacción, que en parte ha venido a menos, es la capacidad de la teología para ponerse a la altura de las ciencias, en lugar de conformarse con el desarrollo de una hermenéutica auto-referencial y normativa que convence sólo a pocos.

\section{Conclusión: misión de la sub-disciplina ciencia-y-teología}

Quizás uno de los puntos de mayor tensión y que requieren más investigación teológica es si se puede proponer dicho diálogo sin caer necesariamente en el naturalismo teológico, como ha ocurrido en bastantes casos. La teología más exigente se siente llamada a reivindicar que el anuncio nuclear del Dios personal trascendente y de la historia puede convivir con un ambiente dominado por la razón científica, y que incluso ese nuevo ambiente puede volverse apto para la fe cristiana.

Rowan Williams, Arzobispo Anglicano de Canterbury, ha publicado recientemente una recensión en el Times Literary Suplement sobre el libro de Conor Cunningham, Darwin's Pious Idea ${ }^{10}$. Sorprende que una figura de

\footnotetext{
${ }^{10}$ Rowan Williams, "Such a Thing: An invigorating journey on the frontier between religion and science", review of: Conor Cunningham, Darwin's Pious Idea: Why the ultra-Darwinists and Creationists both get it wrong, Grand Rapids, MI: Eerdmans, 2010, en Times Literary Suplement, 5638, April 22, 2011, pp. 8-9.
} 
dicho calibre teológico y eclesiástico se interese en primera persona por comentar en tono muy positivo una obra que básicamente reivindica una lectura diferente del darwinismo, que ofrece un espacio amplio a la dimensión divina y a la fe cristiana. Creo que se trata de un ejemplo a seguir.

Queda mucho trabajo por hacer, siempre que aceptemos los retos planteados y seamos capaces de asumir un modelo de elaboración teológica menos auto-referencial y más dialógico, preocupado por la relevancia del mensaje cristiano en el diálogo con la razón y la cultura del propio tiempo. De hecho, el diálogo con la ciencia ofrece seguramente una de las mejores ocasiones para ampliar los horizontes de la Teología fundamental, que se habían vuelto francamente limitados y no albergaban posibilidades de progreso. La teología fundamental puede crecer ante los retos que plantea la ciencia, y recuperar la relevancia que había perdido al asimilarse demasiado al modelo dogmático. 
